\title{
The value of measurement of vaginal fluid creatinine and beta-human chorionic gonadotropin in the diagnosis of premature rupture of membranes
}

\author{
'Zafer BÜTÜN \\ 2Gökhan ÜNVER \\ 3'Masum KAYAPINAR \\ ${ }^{1}$ Gökalp ŞENOL \\ "Kamuran SUMAN
}

1Division of Perinatology, Department of Gynecology and Obstetrics, Eskişehir Osmangazi University Faculty of Medicine, Eskişehir, Turkey

2Department of Gynecology and Obstetrics, Samsun Training and Research Hospital, Samsun, Turkey

${ }^{3}$ Division of Perinatology, Department of Gynecology and Obstetrics, Çukurova University Faculty of Medicine, Adana, Turkey

${ }^{4}$ Department of Perinatology, Afyonkarahisar State Hospital, Afyonkarahisar, Turkey
ORCID ID
ZB : 0000-0001-5297-4462
GÜ : 0000-0002-0887-2634
MK : 0000-0001-6638-1940
GŞ : 0000-0002-9497-3107
KS : 0000-0003-1814-7513

\begin{abstract}
Objective: The purpose of the present study is to evaluate $\beta$-human chorionic gonadotropin ( $\beta-\mathrm{hCG}$ ) and creatinine levels in the vaginal fluid regarding to diagnosis of premature rupture of membranes (PROM).
\end{abstract}

Material and Methods: This study was conducted on 150 pregnant women in the third trimester (28-40 weeks). The patients were grouped as: (1) PPROM group (75 cases) and (2) intact membranes as control group (75 cases). Three milliliters of sterile normal saline were inserted into the posterior fornix of the vagina and then vaginal fluid was aspirated. Creatinine and $\beta$-hCG levels in the vaginal fluid were measured $\beta$-hCG and creatinine levels were compared between the two groups.

Results: The mean vaginal fluid level in Groups 1 and 2 was $0.60 \pm 0.72(0.37)$ and $0.22 \pm 0.11(0.2)$ for creatinine and $\beta$-hCG which was positive in $411.69 \pm 605.65$ (146) and $12.71 \pm 24.63$ (3.9), respectively. There was a statistically significant difference regarding to mean creatinine and $\beta$-hCG levels between two groups $(p<0.001)$. Sensitivity, specificity, positive predictive value, negative predictive value, and accuracy were all $66.67 \%, 96 \%, 94.3 \%, 74.3 \%$, and $81.3 \%$ for creatinine and $94.6 \%, 82.6 \%$, $84.52 \%, 93.94 \%$, and $88.67 \%$ for $\beta$-hCG in detecting PROM with a cutoff value of 0.21 $\mathrm{mg} / \mathrm{dl}$ for creatinine and $16 \mathrm{mIU} / \mathrm{ml}$ for $\beta$-hCG.

Conclusion: Measuring of $\beta$-hCG level in vaginal fluid is accurate, cheap, and simple methods in the diagnosis of PROM. Furthermore, measuring of creatinine level is a simple and accurate method with a lower sensitivity and accuracy than for $\beta$-hCG.

Keywords: Creatinine, premature rupture of membranes, $\beta$-human chorionic gonadotropin.

Cite this article as: Bütün Z, Ünver G, Kayapınar M, Şenol G, Suman K. The value of measurement of vaginal fluid creatinine and beta-human chorionic gonadotropin in the diagnosis of premature rupture of membranes. Zeynep Kamil Med J 2021;52(1):10-15.

Received: August 17, 2020 Accepted: February 01, $2021 \quad$ Online: March 31, 2021

Correspondence: Zafer BÜTÜN, MD. Eskişehir Osmangazi Üniversitesi Tıp Fakültesi, Kadın Hastalıkları ve Doğum Anabilim Dalı, Perinatoloji Bilim Dalı, Eskişehir, Turkey.

Tel: +90222 2392979 e-mail: zaferbutun@hotmail.com

(c) Copyright 2021 by Zeynep Kamil Medical Journal - Available online at www.zeynepkamilmedj.com 


\section{INTRODUCTION}

Premature rupture of membranes (PROM) is rupture of the fetal membranes before the onset of labor and disruption of amniotic membrane integrity. If the disruption in the membranes occurs before 37 weeks of gestation, it is defined as preterm PROM (PPROM). PROM is seen in $10 \%$ of all pregnancies and $80 \%$ of the cases occur in term pregnancy. ${ }^{[1]}$ PPROM accounts for $3-5 \%$ of all pregnancies and is the most common cause of preterm birth. ${ }^{[2]}$ Fetal membranes are more resistant to rupture in early pregnancy. As the gestational age progresses, the membranes begin to weaken and uterine contractions, fetal movements, and increased uterine tension facilitates the rupture of the membranes. ${ }^{[3]}$ In addition, the decrease in the amount of collagen in the membranes near-term increases the risk of rupture. The most important complication of PPROM is preterm birth and related prematurity. ${ }^{[4]}$ Due to the possible complications, it is important to make an accurate diagnosis of PROM. Misdiagnosis of membrane rupture also causes incorrect interventions such as labor induction and prolonged hospital stay. At present, there is no non-invasive, gold standard diagnostic method for the diagnosis of PROM. Direct monitoring of fluid discharge from the cervical os confirms PROM. ${ }^{[5]}$ While the transition of nitrazine paper placed in the vaginal posterior fornix from yellow to dark blue can detect the presence of amniotic fluid in the vagina, many factors such as vaginitis, blood, and semen increase the false positivity rate of the test. [6] Detection of fetal fibronectin in cervicovaginal secretions has been interpreted as a harbinger of labor even in the absence of membrane rupture, with extremely high specificity, but low sensitivity. ${ }^{[7]}$ Another diagnostic method is the detection of insulin-like growth factor (insulin-like growth factor binding protein-1 [IGFBP-1]), which binds to protein-1 and placental alpha microglobulin-1 protein (PAMG1) in cervicovaginal fluids. ${ }^{[8,9]}$ Detection of the PAMG1 in cervicovaginal fluids has high sensitivity and specificity, but the test is not accessible in most centers and is an expensive test. Therefore, alternative tests have been developed and many molecules in the cervicovaginal fluid have been studied. ${ }^{[10]}$

$\beta$-human chorionic gonadotropin ( $\mathrm{hCG}$ ) is found in maternal blood and urine, as well as amniotic fluid. ${ }^{[11]}$ Creatinine is a substance that is excreted by the kidneys. Since most of the amniotic fluid consists of fetal urine, studies have been conducted to investigate the place of creatinine in vaginal washing fluid in the diagnosis of PROM. ${ }^{[12]}$

In this study, we aimed to determine the place and reliability of $\beta$-hCG and creatinine values in the cervicovaginal fluid in the diagnosis of PROM.

\section{MATERIAL AND METHODS}

This study was carried out in the delivery room and obstetrics emergency outpatient clinic of Zeynep Kamil Obstetrics and Gynecology Training and Research Hospital. The ethics committee approval was obtained from the Zeynep Kamil Obstetrics and Gynecology Training and Research Hospital in 2014. The study was defined to have a cross-sectional design. Between May 2014 and November 2014, a total of 150 cases who had been admitted to the emergency delivery room with suspected membrane rupture and hospitalized with confirmed diagnosis of membrane rupture with speculum examination or PAMG-1 test, and cases in the same age group who had been admitted to the emergency delivery room for other reasons and had no vaginal bleeding and vaginal infection, and who had not had intercourse for 3 days, with confirmation of no membrane rupture, were included in the study.

Patients were divided into two groups: 75 patients with confirmed membrane rupture and 75 patients without membrane rupture.

During the routine vaginal examination of the patients, $3 \mathrm{cc}$ sterile saline was injected into the posterior fornix with a speculum and aspirated with the same injector and sent to the biochemistry laboratory for $\beta$-hCG and creatinine evaluation. The $\beta-h C G$ and creatinine values obtained in both groups were compared.

\section{Statistical Analysis}

When evaluating the findings obtained in the study, the IBM SPSS Statistics 15 (SPSS IBM, Turkey) program was used for the statistical analysis. While evaluating the study data, besides the descriptive statistical methods (mean, standard deviation, and frequency), for comparison of the quantitative data, the Student's t-test was used for comparison of the normally distributed parameters between two groups, and the Mann-Whitney U-test was used for comparison of parameters that were not normally distributed between two groups. The Chi-square test was used to compare the qualitative data. The diagnostic accuracy of each test was evaluated with the true- and false-positive rates (sensitivity and [1-specificity]) using the receiver operating characteristic (ROC) curve analysis. In addition, the area under the ROC curve (AUC) with a 95\% confidence interval $(\mathrm{Cl})$ was calculated for each test. The most suitable cutoff points were selected based on the ROC curve analysis. Diagnostic screening tests were used to calculate the sensitivity and specificity. Significance was evaluated at $p<0.05$.

\section{RESULTS}

The study was conducted between May 2014 and November 2014 with a total of 150 female cases, with ages ranging from 16 to 42 years. The mean age of the cases was $27.95 \pm 6.06$ years. The number of pregnancies of the cases ranged from 1 to 8 , with a mean value of $2.34 \pm 1.52$, and with a median value of two pregnancies. The duration of gestation varied between 198 days and 280 days, with a mean value of $258.39 \pm 22.01$ days and a median of 262 days. The cervical openings of the cases varied between $1 \mathrm{~cm}$ and $7 \mathrm{~cm}$, with a mean value of $1.81 \pm 1.31 \mathrm{~cm}$ and a median of $1 \mathrm{~cm}$. The amniotic fluid index ranged from $20 \mathrm{~mm}$ to $260 \mathrm{~mm}$, with a mean value of $101.16 \pm 35.74 \mathrm{~mm}$ and a median of $100 \mathrm{~mm}$. The $\beta-H C G$ levels of the cases ranged from $1.2 \mathrm{mIU} / \mathrm{ml}$ to $3350 \mathrm{mIU} / \mathrm{ml}$, with a mean value of $212.20 \pm 471.74 \mathrm{mIU} / \mathrm{ml}$ and a median of $29.6 \mathrm{mIU} / \mathrm{ml}$. The creatinine levels of the cases ranged from $0.2 \mathrm{mg} / \mathrm{dl}$ to $4.66 \mathrm{mg} / \mathrm{dl}$, with a mean value of $0.41 \pm 0.55 \mathrm{mg} / \mathrm{dl}$ and a median of $0.2 \mathrm{mg} / \mathrm{dl}$. While it was PROM (+) in $75(50 \%)$ of the cases, it was PROM (-) in $75(50 \%)$ of the cases.

While 70 of the cases (46.7\%) had no history of previous birth, 50 (33.3\%) had a history of normal spontaneous birth and $30(20 \%)$ had a history of cesarean section. While $70(46.7 \%)$ of the cases were nulliparous, $80(53.3 \%)$ of them were multiparous (Table 1$)$. 


\begin{tabular}{|c|c|c|c|c|c|c|c|}
\hline & \multicolumn{3}{|c|}{ PROM (+) } & \multicolumn{3}{|c|}{ PROM (-) } & \multirow[t]{2}{*}{$\mathbf{p}$} \\
\hline & Mean \pm SD (Median) & $\mathbf{n}$ & $\%$ & Mean $\pm S D$ (Median) & $\mathbf{n}$ & $\%$ & \\
\hline${ }^{1}$ Age & $27.34 \pm 5.94$ & & & $28.56 \pm 6.17$ & & & 0.222 \\
\hline${ }^{2}$ Number of pregnancy & $2.29 \pm 1.59(2)$ & & & $2.39 \pm 1.46(2)$ & & & 0.428 \\
\hline${ }^{2}$ Pregnancy duration & $260.7 \pm 21.33(265)$ & & & $255.81 \pm 22.51(259)$ & & & 0.078 \\
\hline${ }^{2}$ Cervical opening & $2.29 \pm 1.54(2)$ & & & $1.32 \pm 0.79(1)$ & & & $0.001^{*}$ \\
\hline${ }^{2}$ Amniotic fluid index & $93.32 \pm 37.13(100)$ & & & $109.00 \pm 32.69(110)$ & & & $0.004^{*}$ \\
\hline${ }^{3}$ Previous birth & & & & & & & $0.001^{*}$ \\
\hline Normal spontaneous delivery & & 32 & 42.7 & & 18 & 24 & \\
\hline $\mathrm{C} / \mathrm{S}$ & & 6 & 8 & & 24 & 32 & \\
\hline No births & & 37 & 49.3 & & 33 & 44 & \\
\hline${ }^{3}$ Parity & & & & & & & 0.513 \\
\hline Nulliparous & & 37 & 49.3 & & 33 & 44 & \\
\hline Multiparous & & 38 & 50.7 & & 42 & 56 & \\
\hline
\end{tabular}

PROM: Premature rupture of membranes; SD: Standard deviation; 1: Student's t-test; 2: Mann-Whitney U-test; 3: Chi-square test; *: P<0.01.

Table 2: Evaluation of $\beta-H C G$ and creatinine according to PROM

\begin{tabular}{lccc} 
& PROM (+) & PROM (-) & p \\
& Mean \pm SD (Median) & Mean \pm SD (Median) & \\
\hline B-hCG & $411.69 \pm 605.65(146)$ & $12.71 \pm 24.63(3.9)$ & $\mathbf{0 . 0 0 1}^{*}$ \\
Creatinine & $0.60 \pm 0.72(0.37)$ & $0.22 \pm 0.11(0.2)$ & $\mathbf{0 . 0 0 1}^{*}$
\end{tabular}

Mann-Whitney U-test; PROM: Premature rupture of membranes; SD: Standard deviation; $\beta$-hCG: $\beta$-human chorionic gonadotropin; *: $P<0.01$.

There was no statistically significant difference between the PROM (+) cases and the PROM (-) cases in terms of mean age, number of pregnancies, and duration of gestation $(p>0.05)$. The cervical opening rates of the cases with PROM (+) were found to be statistically significantly higher than the cases with PROM $(-)(p$ : $0001 ; p<0.01)$. The amniotic fluid index level of the cases with PROM (+) was found to be statistically significantly lower than cases with PROM (-) (p: 0.004; p<0.01).

There was a statistically significant difference between the previous delivery types of cases with PROM (+) and cases with PROM $(-)$ ( $p: 0.001 ; p<0.01)$. In cases with PROM $(+)$, the rate of normal spontaneous delivery of the previous delivery type was significantly higher than the cases with PROM (-), and in cases with PROM (-), the rate of previous delivery being $\mathrm{C} / \mathrm{S}$ was significantly higher than cases with PROM (+). There was no statistically significant difference between the parity distributions of the cases with PROM (+) and the cases with PROM (-) ( $p>0.05)$ (Table 1).

The $\beta$-hCG level of the cases with PROM (+) was found to be statistically significantly higher than the cases with PROM (-) (p: 0001; $p<0.01)$. The creatinine level of the cases with PROM (+) was found to be statistically significantly higher than the cases with PROM (-) (p: 0001; p<0.01) (Table 2).

In determining the cutoff point for $\beta$-hCG, diagnostic screening tests and sensitivity and specificity calculations were made for different points at regular intervals and the ROC curve was drawn. The area under the curve value was 0.963 (AUC: $0.963 ; 95 \% \mathrm{Cl}$ : 0.936-0.989) (Fig. 1). The cutoff values for $\beta$-hCG were calculated separately. When the cutoff value for $\beta-\mathrm{hCG}$ was taken as $16 \mathrm{mlu} /$ $\mathrm{ml}$, the sensitivity and specificity were determined as $94.67 \%$ and $82.67 \%$, and the accuracy rate as $88.67 \%$ (Table 3 ).

In determining the cutoff point for creatinine, diagnostic screening tests and sensitivity and specificity calculations were made for different points at regular intervals and the ROC curve was drawn. The area under the curve value was 0.813 (AUC: $0.813 ; 95 \% \mathrm{Cl}$ : $0.741-0.885$ ) (Fig. 2). The cutoff point determined for creatinine in PROM diagnosis was 0.21 . The sensitivity of this value was $66.67 \%$ and the specificity was $96 \%$ (Table 4).

\section{DISCUSSION}

PPROM is one of the most common causes of fetal morbidity and mortality. For this reason, it is important to make a correct diagnosis in PPROM, to prevent possible complications, and to reduce the length of stay in the hospital in case of a wrong diagnosis. Fluid drainage from the cervical os is observed in the speculum examination in the majority of patients admitted to the hospital with the complaint of vaginal discharge. The remaining patient group, that is, patients with no fluid discharge at the time of examination, constitutes the main difficulty in the diagnosis of PROM. Similar methods such as nitrazine $(\mathrm{pH})$ test and the fern test, which have been used frequently in the diagnosis of PROM until today, 


\begin{tabular}{|c|c|c|c|c|c|}
\hline Value & Sensitivity & Specificity & $\begin{array}{c}\text { Positive } \\
\text { predictive } \\
\text { value }\end{array}$ & $\begin{array}{c}\text { Negative } \\
\text { predictive } \\
\text { value }\end{array}$ & Accuracy \\
\hline 4 & 100.00 & 50.67 & 66.96 & 100.00 & 75.33 \\
\hline 5 & 100.00 & 56.00 & 69.44 & 100.00 & 78.00 \\
\hline 6 & 100.00 & 61.33 & 72.12 & 100.00 & 80.67 \\
\hline 7 & 98.67 & 61.33 & 71.84 & 97.87 & 80.00 \\
\hline 8 & 98.67 & 64.00 & 73.27 & 97.96 & 81.33 \\
\hline 9 & 96.00 & 65.33 & 73.47 & 94.23 & 80.67 \\
\hline 12 & 96.00 & 69.33 & 75.79 & 94.55 & 82.67 \\
\hline 13 & 96.00 & 73.33 & 78.26 & 94.83 & 84.67 \\
\hline 14 & 94.67 & 76.00 & 79.78 & 93.44 & 85.33 \\
\hline 15 & 94.67 & 77.33 & 80.68 & 93.55 & 86.00 \\
\hline 16 & 94.67 & 82.67 & 84.52 & 93.94 & 88.67 \\
\hline 21 & 93.33 & 84.00 & 85.37 & 92.65 & 88.67 \\
\hline 22 & 92.00 & 85.33 & 86.25 & 91.43 & 88.67 \\
\hline
\end{tabular}

Table 4: Cut-off point detection for creatinine

\begin{tabular}{lccccc} 
Value Sensitivity Specificity & $\begin{array}{c}\text { Positive } \\
\text { predictive } \\
\text { value }\end{array}$ & $\begin{array}{c}\text { Negative } \\
\text { predictive } \\
\text { value }\end{array}$ \\
& & \multicolumn{5}{c}{ Accuracy } \\
\hline 0.21 & 66.67 & 96.00 & 94.34 & 74.23 & 81.33 \\
0.22 & 61.33 & 96.00 & 93.88 & 71.29 & 78.67 \\
0.25 & 60.00 & 96.00 & 93.75 & 70.59 & 78.00 \\
0.28 & 57.33 & 96.00 & 93.48 & 69.23 & 76.67 \\
0.3 & 53.33 & 97.33 & 95.24 & 67.59 & 75.33 \\
0.35 & 52.00 & 97.33 & 95.12 & 66.97 & 74.67 \\
0.4 & 46.67 & 97.33 & 94.59 & 64.60 & 72.00 \\
\hline
\end{tabular}

do not have sufficient reliability and there is still no non-invasive gold standard method, and this has led to the search for new tests IGFBP-1, alpha-fetoprotein, prolactin, fibronectin, $\beta-h C G$, and PAMG1. Although the sensitivity and specificity of the PAMG1 test are high, the difficulty for accessibility and its high cost limit its use. In addition to these tests, the presence of urea, creatinine, AST, and ALT, which have been proven to be present in amniotic fluid and in vaginal washing fluid, has been attempted to be used in the diagnosis of PROM.

In the second and third trimesters, most of the amniotic fluid consists of fetal urine. Creatinine filtered from fetal kidneys passes into amniotic fluid through urine. $\beta$-hCG is also a substance produced by trophoblastic tissue, found in different concentrations in maternal blood, urine, and amniotic fluid, and is easy to detect. ${ }^{[13]}$ The

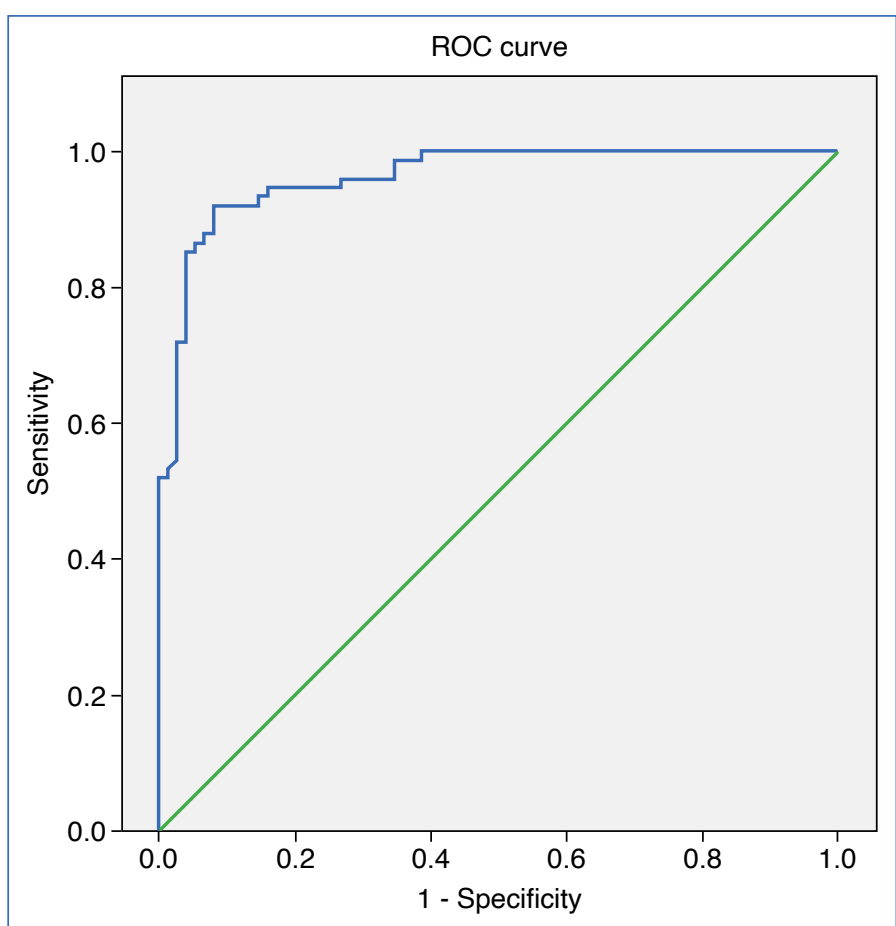

Figure 1: Receiver operating characteristic curve for $\beta$-human chorionic gonadotropin.

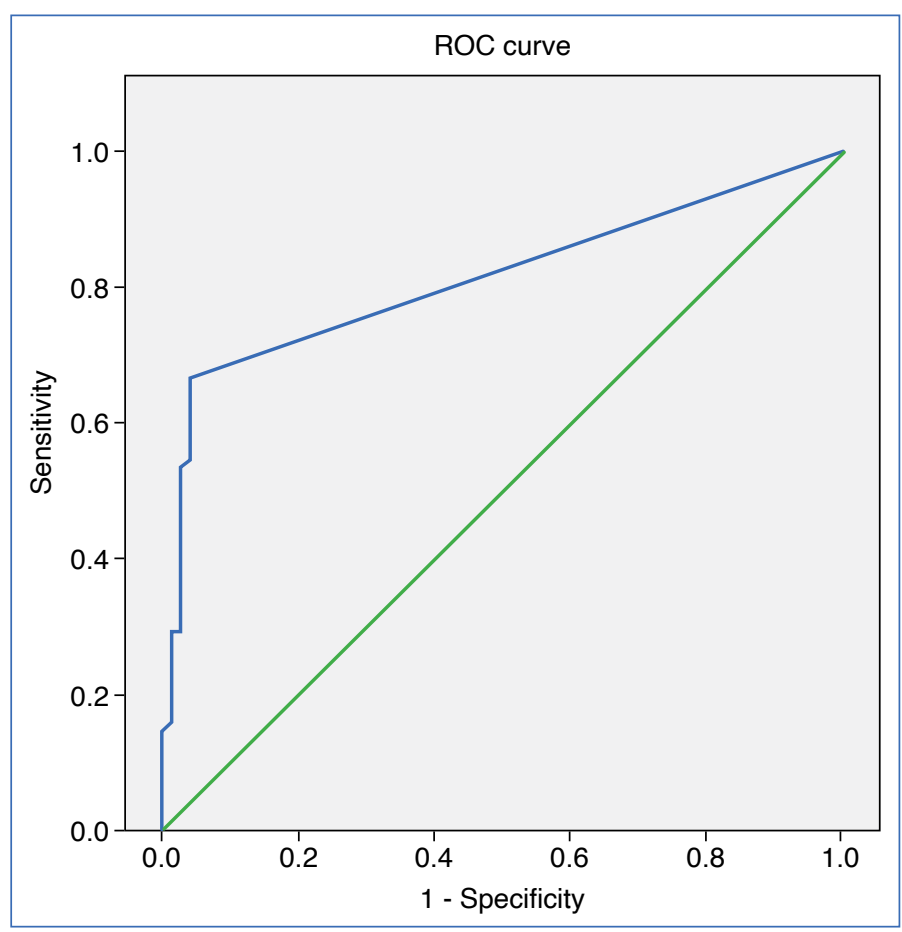

Figure 2: Receiver operating characteristic curve for creatine.

presence of these two substances in low concentrations in vaginal secretions and the increase in the concentration in the vagina after amniotic drainage in PROM means that the use of these substances may be appropriate in the diagnosis of PROM. In our study, we investigated the place of $\beta-\mathrm{hCG}$ and creatinine values in vaginal 
washing fluid in the diagnosis of PROM. In our study, we found that $\beta$-hCG values and creatinine values in the vaginal washing fluid in the PROM group were statistically significantly higher than the nonPROM group $(p<0.001)$.

In the study conducted by Ghasemi et al. ${ }^{[10]}$ in 2016, it was found that prolactin and $\beta-\mathrm{hCG}$ in vaginal washing fluid had higher sensitivity than urea and creatinine in the diagnosis of PROM. In this study, despite the high sensitivity and specificity of the PAMG1 test, the accessibility and cost were shown as disadvantages. It has been emphasized that $\beta-\mathrm{hCG}$ can be used in the diagnosis of PROM in suspicious cases.

In the study conducted by Cooper et al., ${ }^{[14]}$ when the beta-hCG cutoff value in the vaginal washing fluid was determined as $50 \mathrm{mIU} /$ $\mathrm{mL}$ for the diagnosis of PROM, the sensitivity, specificity, and negative and positive predictive values (PPVs) were found to be $96 \%$, $79 \%, 95 \%$, and $84 \%$, respectively. In this study, it was found that $\beta$-hCG can be used in the diagnosis of PROM.

In the study conducted by Zanjani et al., ${ }^{[13]}$ when the creatinine cutoff value in the vaginal washing fluid was determined as $0.5 \mathrm{mg} /$ dl for the diagnosis of PROM, the sensitivity, specificity, and negative and PPVs were found to be $96.7 \%, 100 \%, 100 \%$, and $96.8 \%$, respectively. In this study, it was found that creatinine could be used in the diagnosis of PROM.

In the study conducted by Ahmed Mohamed et al., ${ }^{[15]} \beta-h C G$, creatinine, and urea were examined in vaginal washing fluid for the diagnosis of endoscopic mucosal resection (EMR). The cutoff values for $\beta$-hCG and creatinine were determined as $20 \mathrm{mIU} / \mathrm{ml}$ and 0.31 $\mathrm{mg} / \mathrm{dl}$. The sensitivity, specificity, and negative and PPVs for $\beta$-hCG were determined as $83 \%, 100 \%, 100 \%$, and $85.6 \%$, respectively. The sensitivity, specificity, and negative and PPVs for creatinine were determined as $100 \%, 100 \%, 100 \%$, and $100 \%$, respectively. In this study, it was found that $\beta-\mathrm{hCG}$ and creatinine could be used in the diagnosis of PROM.

In the study conducted by Tığlı et al., ${ }^{[16]} \beta-\mathrm{hCG}$, creatinine, and urea were examined in the vaginal washing fluid for the diagnosis of PROM, and the cutoff values for $\beta$-hCG and creatinine were taken as $50 \mathrm{mlU} / \mathrm{ml}$ and $0.30 \mathrm{mg} / \mathrm{dl}$. The sensitivity, specificity, and negative and PPVs for $\beta$-hCG were determined as $85.3 \%, 93.3 \%, 92.7 \%$, and $86.4 \%$, respectively. The sensitivity, specificity, and negative and PPVs for creatinine were determined as $46.6 \%, 94.6 \%, 83.7 \%$, and $63.9 \%$, respectively. In this study, it was found that $\beta$-hCG was superior to other parameters in the diagnosis of PROM.

A study published in 2019 found that the use of creatinine in the vaginal washing fluid could be used with $94.4 \%$ sensitivity and $93.3 \%$ specificity. In this study, it was stated that although the PAMG1 test was the gold standard in today's conditions, its high cost and having difficulty in transportation led to the search for new tests. ${ }^{[17]}$

In our study, when we determined the $\beta$-hCG cutoff value in the vaginal washing fluid as $16 \mathrm{mIU} / \mathrm{dL}$, the sensitivity, specificity, PPV, negative predictive value (NPV), and the accuracy rate were found as $94.67 \%, 82.67 \%, 84.62 \%, 93.94 \%$, and $88.67 \%$, respectively. When we determined the cutoff value of creatinine in the vaginal washing fluid as $0.21 \mathrm{mg} / \mathrm{dL}$, we found the sensitivity, specificity, PPV and NPV, and the accuracy rate as $66.67 \%, 96 \%, 94.34 \%, 74.23 \%$, and $81.33 \%$, respectively.
As a result, we determined that the $\beta$-hCG value in the vaginal washing fluid could be used in the diagnosis of PROM. Although creatinine can also be used for diagnosis, it has a lower sensitivity and accuracy rate than $\beta$-hCG.

When we set the cutoff value for $\beta$-hCG as $16 \mathrm{mlU} / \mathrm{dL}$, we obtained similar results to other EMR diagnostic tests, in accordance with the literature. ${ }^{[13-19]}$ Compared to these tests, the fact that $\beta-\mathrm{HCG}$ measurement in vaginal fluid is cheaper, availability, and easy applicability indicates that this test can be used as an alternative to other expensive tests for the diagnosis.

\section{Statement}

Ethics Committee Approval: The Zeynep Kamil Obstetrics and Gynecology Training and Research Hospital Clinical Research Ethics Committee granted approval for this study (date: 23.05.2014, number: 85).

Informed Consent: Written informed consent was obtained from patients who participated in this study.

Peer-review: Externally peer-reviewed.

Author Contributions: Concept - ZB; Design - ZB, GÜ; Supervision - GÜ, MK; Resource - ZB, KS; Materials - ZB, GŞ; Data Collection and/or Processing - ZB, MK; Analysis and/or Interpretation - GŞ, KS; Literature Search - ZB, GÜ; Writing - ZB, KS; Critical Reviews - ZB, MK.

Conflict of Interest: The authors have no conflict of interest to declare.

Financial Disclosure: The authors declared that this study has received no financial support.

\section{REFERENCES}

1. Mercer BM. Preterm premature rupture of the membranes. Obstet Gynecol 2003;101(1):178-93.

2. Aagaard-Tillery KM, Nuthalapaty FS, Ramsey PS, Ramin KD. Preterm premature rupture of membranes: Perspectives surrounding controversies in management. Am J Perinatol 2005;22(6):287-97.

3. Garite TJ. Management of premature rupture of membranes. Clin Perinatol 2001;28(4):837-47.

4. Meis PJ, Goldenberg RL, Mercer BM, lams JD, Moawad AH, Miodovnik $M$, et al. The preterm prediction study: Risk factors for indicated preterm births. Maternal-fetal medicine units network of the national Institute of child health and human development. Am J Obstet Gynecol 1998;178(3):562-7.

5. Gibbs RS, Karlan BY, Haney AF, Nygaard I. Erken membran rüptürü. In: Danforth's Obstetrik ve Jinekoloji. 10 ${ }^{\text {th }}$ ed. Baskı. Ankara: Güneş Tıp Kitabevleri; 2010. p. 186-976.

6. Davidson KM. Detection of premature rupture of the membranes. Clin Obstet Gynecol 1991;34(4):715-22.

7. Abbott DS, Radford SK, Seed PT, Tribe RM, Shennan AH. Evaluation of a quantitative fetal fibronectin test for spontaneous preterm birth in symptomatic women. Am J Obstet Gynecol 2013;208(2):122.e1-6.

8. Akercan F, Cirpan T, Kazandi M, Terek MC, Mgoyi L, Ozkinay E. The value of the insulin-like growth factor binding protein-1 in the cervical-vaginal secretion detected by immunochromatographic dipstick test in the prediction of delivery in women with clinically unconfirmed preterm premature rupture of membranes. Eur J Obstet Gynecol Reprod Biol 2005;121(2):159-63.

9. Lee SE, Park JS, Norwitz ER, Kim KW, Park HS, Jun JK. Measurement of placental alpha-microglobulin-1 in cervicovaginal discharge to diag- 
nose rupture of membranes. Obstet Gynecol 2007;109(3):634-40.

10. Ghasemi M, Jaami R, Alleyassin A, Ansarimoghaddam A. The value of urea, creatinine, prolactin, and beta sub-unit of human chorionic gonadotropin of vaginal fluid in the diagnosis of premature preterm rupture of membranes in pregnancy. Turk J Obstet Gynecol 2016;13(2):62-6.

11. Anai T, Tanaka $Y$, Hirota $Y$, Miyakawa I. Vaginal fluid hCG levels for detecting premature rupture of membranes. Obstet Gynecol 1997;89(2):261-4.

12. Kafali $\mathrm{H}$, Oksüzler $\mathrm{C}$. Vaginal fluid urea and creatinine in diagnosis of premature rupture of membranes. Arch Gynecol Obstet 2007;275(3):157-60.

13. Zanjani MS, Haghighi L. Vaginal fluid creatinine for the detection of premature rupture of membranes. J Obestet Gynaecol Res 2011;38(3):505-8.

14. Cooper AL, Vermillion ST, Soper DE. Qualitative human chorionicgonadotropin testing of cervicovaginal washings for the detection of preterm premature rupture of membranes. Am J Obstet Gynecol 2004;191(2):593-7.
15. Mohamed AM, Mostafa WA. The value of measurement of vaginal fluid urea, creatinine and beta HCG in the diagnosis of premature rupture of membranes. Kasr Al-Aini J Obstet Gynecol 2011;2(2):41-7.

16. Tığı A, Kurt S, Kopuz A. Erken membran rüptürü tanısında vajinal yıkama sıvısında beta-insan koryonik gonadotropin, kreatinin ve ürenin yeri. Perinatol Derg 2014;22(4):133-7.

17. Kuruoğlu YS, Bıldırcın FD, Karlı P, Özdemir AZ. Use of vaginal creatinine levels in detecting premature rupture of membranes Erken memran rüptürü tespitinde vajinal kreatinin seviyelerinin kullanılması. J Surg Med 2019;3(6):421-7.

18. Abdelazim IA, Makhlouf HH. Placental alpha microglobulin-1 (AmniSure ${ }^{\circledR}$ test) for detection of premature rupture of fetal membranes. Arch Gynecol Obstet 2012;285(4):985-9.

19. Kariman N, Hedayati M, Majd SA. The diagnostic power of cervico-vaginal fluid prolactin in the diagnosis of premature rupture of membranes. Iran Red Crescent Med J 2012;14(9):541-8. 